\title{
EFECTOS GEOMORFOLÓGICOS DE FUERTES VIENTOS SOBRE PLAYAS. EL CASO DE LA PLAYA DE PEHUEN CO, ARGENTINA
}

\author{
M.L. BUSTOS ${ }^{(1)^{*}}$, M.C. PICCOLO ${ }^{(1,2)}$, G.M.E. PERILLO ${ }^{(1,3)}$ \\ ${ }^{1}$ Instituto Argentino de Oceanografía. \\ CC 840 B8000FWB, Bahía Blanca, Argentina. \\ 2 Departamento de Geografía y Turismo. 12 de Octubre y San Juan. \\ B8000FWB, Bahía Blanca, Argentina. \\ ${ }^{3}$ Departamento de Geología. San Juan 670. \\ B8000FWB, Bahía Blanca. Argentina.
}

RESUMEN. El objetivo de esta investigación fue analizar el efecto de los vientos fuertes sobre la erosión y cambios geomorfológicos de la playa de la villa balnearia Pehuén Co (Buenos Aires, Argentina). Se estudiaron cuatro sectores de costa del balneario de diferentes características y orientaciones. Se analizaron datos de viento de una estación meteorológica localizada en la costa y se midieron mensualmente perfiles de playa durante el período 2007-2009. También se estudió la granulometría del médano, espaldón, berma y línea de bajamar. Los resultados mostraron que dependiendo de la dirección del viento los efectos fueron diferentes en cada sector. La zona Oeste y Centro fueron las más perjudicadas ante eventos del cuadrante SW. En cambio las zonas Este y la Reserva fueron afectadas por erosión $\left(13 \mathrm{~m}^{3}\right)$ con los vientos del cuadrante SE. Con estos resultados se desarrolló un mapa de vulnerabilidad de la costa.

Geomorphologic changes on beaches as a result of strong winds. The case of the Pehuen Co beach, Argentina

ABSTRACT. The effect of strong winds on the erosion and geomorphological changes in Pehuen Co beach (Buenos Aires, Argentina) were analyzed. Although four different sectors of the coast with variable orientations were identified, in all cases the beach is dissipative with two or three parallel bars. The West Zone $(Z W)$ is an extensive beach composed of medium to fine sand, backed by dunes covered with tamarisx gallica and a coastal road that artificially modified the dunes resulting in a cliffy backshore. The Center Zone (ZC), more urbanized, has beach less extense and dominated by fine sand; dunes covered with tamarisx gallica. The East Zone (ZE) has the widest beaches and medium sand; it coincides 
with the end of the urbanization. Finally the Reserve Zone $(Z R)$, where there are trace fossils, is the most extensive and widest beach with fine sand and dunes naturally vegetated; it has no roads or infrastructure. Wind data from a meteorological station located on the coast and related to the monthly beach profiles during the period 2007-2009 were analyzed. The events offshore winds (SE and $S W$ quadrants) were identified. It was determined that $40 \mathrm{~km} \mathrm{~h}^{-1}$ is threshold of wind speed and durations greater than $6 \mathrm{~h}$ are required to significantly affect coastal geomorphology. The results showed that different wind directions generate erosion and/or accretion in each sector. 91 events were recorded, most of the SW quadrant. The West and Central zones were the most vulnerable to events from $S W$ quadrant. The East zones were eroded $\left(13 \mathrm{~m}^{3}\right)$ by the winds from the SE quadrant. Based on this analysis, a map of coastal vulnerability was developed showing that the western and central zones were the most vulnerable. The other two zones had a middle and lower vulnerability most likely due their natural stages not affected anthropogenic factors.

Palabras clave: viento, perfiles de playa, cambios geomorfológicos, mapa de vulnerabilidad, Pehuén Co (Buenos Aires, Argentina).

Key words: wind, beach profile, geomorphological changes, vulnerability map, Pehuén Co (Buenos Aires, Argentina).

Enviado el 16 de diciembre de 2010 Aceptado el 11 de abril de 2011

*Correspondencia: Instituto Argentino de Oceanografía. CC 840 B8000FWB, Bahía Blanca, Argentina. E. mail: mlbustos@criba.edu.ar

\section{Introducción}

Las playas cambian su morfología constantemente debido a la acción de olas, corrientes, mareas y vientos. Eventos extremos excepcionales pueden producir grandes modificaciones en cortos períodos de tiempo (Birkemeier, 1979; Lizarraga-Arcienaga et al., 2007). Durante estos eventos el agua aplana el perfil de playa e invade la costa, llegando al pie del médano e inclusive, más ocasionalmente, erosionando la cara del mismo (Leatherman, 1979). El sedimento, además de ser movilizado a lo largo de la costa por las corrientes litorales, es transportado costa afuera y depositado fundamentalmente en las barras de rompiente (Perillo, 2003). Durante los períodos de calma, la playa tiende a recuperarse a partir de la acción acumulativa de olas de largo período con la migración de las barras hacia la playa.

Las playas y médanos actúan como defensa de la zona costera contra los temporales marinos. Este ciclo natural se destruye cuando comienzan los asentamientos urbanos masivos e incontrolados (Piedra-Cueva, 2006; Benavente et al., 2007). La zona litoral amortigua el intercambio de energía, básicamente del oleaje y del viento y, por otro lado, 
la ocupación antrópica desmedida reduce la franja costera haciéndola más vulnerable a los efectos de las tormentas (Del Pozo et al., 2000; Hill et al., 2004).

A nivel internacional estos fenómenos extremos y sus consecuencias sobre las geoformas de las playas se estudian exhaustivamente desde hace varias décadas. Algunos de estos trabajos presentan el estudio de diversas tormentas y sus efectos erosivos en la costa, llegando a conclusiones similares de previsión y sugiriendo la identificación de zonas litorales vulnerables a las tormentas y olas (Birkemeier, 1979; Reyes et al., 1999; Gibeaut et al., 2002 y Benavente et al., 2007). También se han realizado estudios clasificando estos eventos según el tipo de olas, vientos, ondas de tormenta, nivel medio del mar o combinación de estos parámetros. En la bahía de Sandy Hook en Nueva Jersey, debido al gran aumento del nivel del mar registrado entre 1900 y 1977, se realizó un estudio de la erosión de playa en base a la variación del balance sedimentario. Entre los métodos aplicados se realizó un índice de tormentas basado en la velocidad media del viento y su duración. De esta forma se encontró una relación entre el aumento del nivel del mar y el aumento en los valores del índice propuesto (Allen, 1981). Para la zona del litoral catalán se realizó una clasificación de cinco tipos de tormentas dependiendo de la duración y altura medias de las olas, logrando así identificar las zonas con mayor riesgo potencial al impacto de estos eventos (Mendoza y Jiménez, 2008).

En la costa de Mar del Plata, en la provincia de Buenos Aires (Argentina), se aplicó un índice de erosión potencial de tormentas basado en las mediciones horarias del nivel medio del mar, encontrando un incremento promedio del índice de un $7 \%$ respecto de la década anterior (Fiore et al., 2009). En el Norte de la misma provincia (Bértola et al., 2006) y en el Sudoeste (Caló et al., 2000) se investigaron los efectos que diferentes eventos de tormenta generaron sobre la playa concluyendo que los trenes de olas provenientes del Sudeste, ocasionan los mayores daños en la costa. Los eventos denominados "Sudestadas" incrementan la acción erosiva del oleaje y producen un importante ascenso del nivel medio del mar (Marcomini y López, 1997). También los eventos del SW ocasionan grandes daños sobre algunos sectores de la costa al sur de la provincia de Buenos Aires, según se registró en las costas de Pehuén Co con el evento del 26 de julio de 2007 (Bustos et al., 2009).

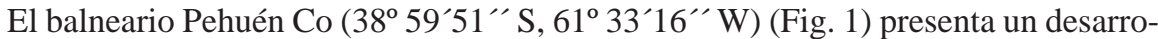
llo turístico que aumenta año tras año, ingresando más de 600000 turistas entre diciembre y febrero. Su paisaje posee médanos sin vegetar, médanos cubiertos por tamariscos (Tamarix gallica), acantilados artificiales y afloramientos de arena cementada. Actualmente se observa una erosión importante y de diferente magnitud de sus playas.

La investigación de la erosión sobre las playas debe realizarse estudiando el comportamiento de todos los parámetros oceanográficos y meteorológicos que actúan en conjunto erosionando o acrecionando sedimento sobre la costa. En Pehuén Co no se han efectuado mediciones de olas y mareas, si bien existen dos bases de datos de olas cercanas. Una de ellas, la más próxima al área de estudio, es una torre mareográfica que brinda datos de altura y período de olas pero no de dirección. Esta se encuentra demasiado cercana a la desembocadura del canal Principal del estuario de Bahía Blanca 


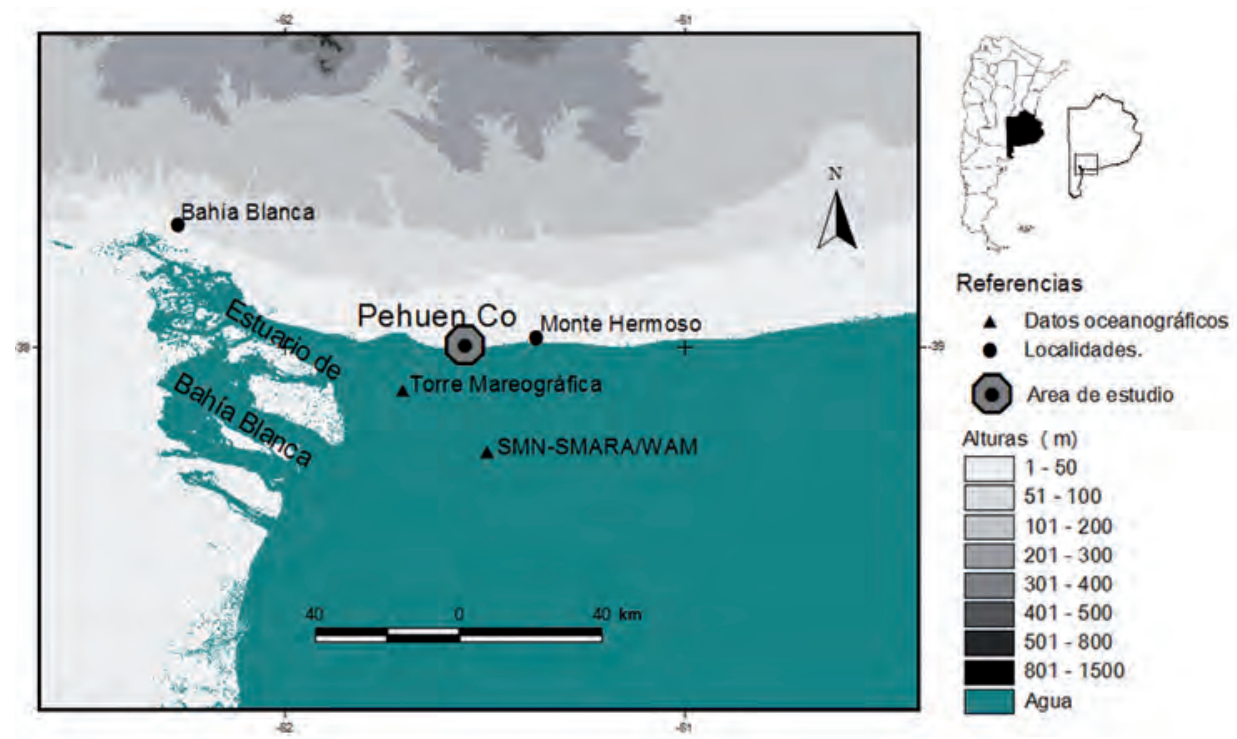

Figura 1. Localización del área de estudio en el Sur de la provincia de Buenos Aires (Argentina).

(Fig. 1) por lo cual no es representativa del tipo de olas que afectan al balneario de estudio. La otra, del Servicio Meteorológico Nacional provee datos de olas basados en el modelo numérico SMARA/WAM. Recientes estudios demostraron que tampoco representa la verdadera altura de olas para este sector de costa (Delgado et al., 2009). Por estos motivos no se cuenta con datos de olas y mareas en la zona.

Un estudio de las tormentas que afectan a este sector es necesario debido al rápido desarrollo turístico y a la puesta en valor de sus tierras cada vez más parceladas. El único dato a escala local disponible para el estudio de los cambios geomorfológicos de la playa de la villa balnearia es la información meteorológica. El viento ocasiona erosión generando el movimiento de médanos vivos. Por otro lado, existe una relación directa entre la velocidad del viento local y la altura de las olas en una costa (Allen, 1981). Por lo tanto, en este trabajo se utiliza la información de viento para estimar cambios geomorfológicos en una playa.

La costa de Pehuén Co posee una orientación Oeste-Este por lo cual los vientos procedentes del continente (cuadrantes NE y NW) no generan olas de alturas importantes. Ocurre lo contrario con los vientos que soplan hacia la costa. Estos vientos influyen sobre las olas locales y aumentan la altura de las pleamares. Por ello el objetivo de este trabajo es investigar el efecto geomorfológico de los fuertes vientos provenientes del mar sobre la costa del balneario Pehuén Co e indicar áreas vulnerables a la erosión. 


\section{Marco Físico}

La localidad de Pehuén Co se ubica al sudoeste de la provincia de Buenos Aires, en el partido de Coronel de Marina Leonardo Rosales (Fig. 1). Es una playa disipativas con dos o tres barras paralelas. Las mareas son semidiurnas, con un nivel medio de 1,94 m por encima del plano de reducción. La altura media de pleamar es de 3,12 m y la de bajamar de 0,76 m (SHN, 2010). Según mediciones realizadas entre los años 1986-87 (Caló et al., 1987), la dirección predominante de las olas es del S (75,8\% de las observaciones), con alturas entre 0,3 y $0,6 \mathrm{~m}(60,5 \%)$ y período promedio de $8,8 \mathrm{~s}$. Por otra parte, las rompientes son de tipo de derrame $(83,3 \%)$ y las corrientes litorales predominantes son las que fluyen con dirección E (Caló et al., 1987).

Según datos de la estación meteorológica localizada en Pehuén Co, la temperatura media anual es $13,6^{\circ} \mathrm{C}$. Las temperaturas en primavera-verano presentan un promedio de $16,7^{\circ} \mathrm{C}$ mientras que en otoño-invierno el promedio es de $9,9^{\circ} \mathrm{C}$. La temperatura máxima media anual es $27,1^{\circ} \mathrm{C}$ y la mínima media anual $3,5^{\circ} \mathrm{C}$. La precipitación anual de esta zona se encuentra en los 326 mm, estimados para el período 2005-2009, con una máxima en el año 2007 de 489 mm. Es una región de períodos húmedos y secos alternados. Normalmente, las lluvias se concentran en primavera-verano, decrecen en otoño, haciéndose mínimas en invierno. La presión media anual es de $1017 \mathrm{hPa}$. La correspondiente a los meses de enero es de 1013,5 hPa, mientras que en julio es de 1019,8 hPa. Los vientos predominantes son del N y NW (Capelli de Steffens y Campo de Ferreras, 1994), soplando con mayor intensidad en los meses de primavera y verano, principalmente en diciembre y enero. Su velocidad media anual oscila entre 7 y $25 \mathrm{~km} \mathrm{~h}^{-1}$ (Fig. 2).

El balneario se encuentra sobre una saliente conocida como punta Pehuén Co, en el cual está emplazado el centro urbano. Esta característica le otorga rasgos especiales en cuanto a su dinámica y morfología costera. Por esta saliente se pueden distinguir en el área costera cuatro zonas: zona Oeste (ZW), zona Centro (ZC), zona Este (ZE) y una zona más alejada, sin urbanización, donde se emplaza una Reserva Geológica, Paleontológica, Arqueológica y Natural Pehuén Co-Monte Hermoso (ZR) (Fig. 3) (Tabla 1). A continuación se describen las características de cada zona.

Zona Oeste $(Z W)$ : Con una orientación WNW-ESE, posee dos tipos de costa. Hacia el Oeste no hay urbanización y el médano costero presenta alturas entre 1 y $3 \mathrm{~m}$. Son médanos de escasa movilidad y parcialmente cubiertos con vegetación herbácea. La urbanización comienza con un parador y continúa con una calle costanera sobre el espaldón del médano. Este espaldón fue modificado por procesos artificiales y se asemeja a un acantilado. Comenzó a formarse al construir la calle costanera sobre el médano vegetado con tamariscos (Tamarix gallica). En 1997, debido a una importante tormenta que removió estas plantas y la presencia de la calle costanera, se erosionó el lugar dando como resultado una estructura similar a un acantilado por sus pendientes altas. El parador comparte su salida a la playa con las lanchas de pescadores artesanales los cuales transitan con vehículos de mediano y gran porte (tractores, camiones, camionetas) para transportarlas hasta el agua. 


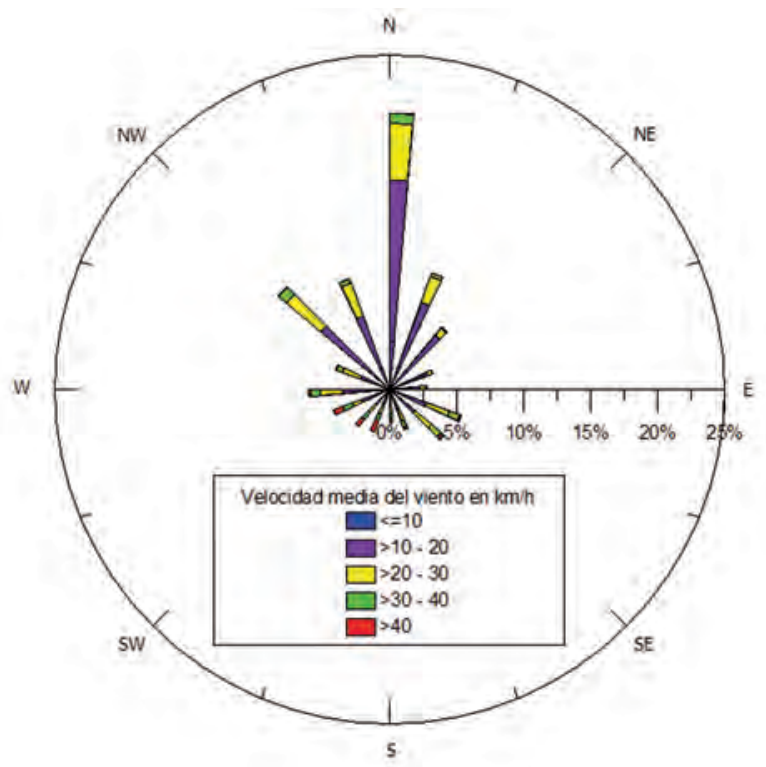

Figura 2. Rosa de los vientos basada en la velocidad media de la localidad de Pehuén Co.

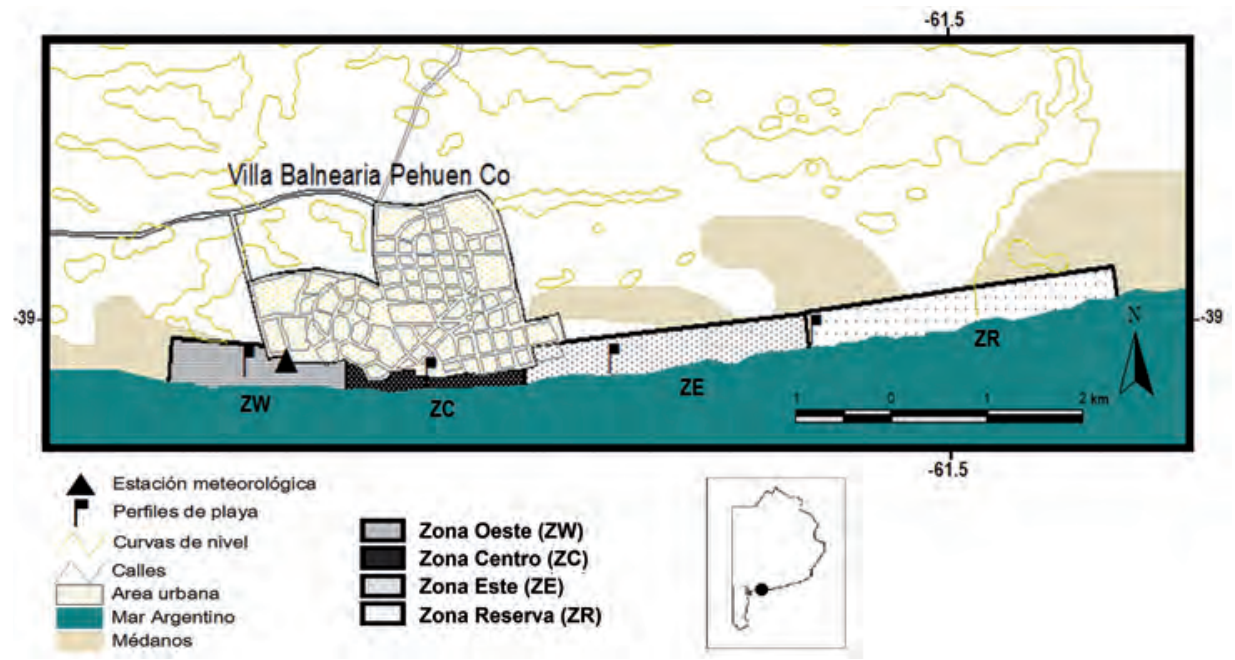

Figura 3. Localización de las zonas de costa estudiadas. Donde ZW es la zona Oeste, ZC es la zona Centro, ZE es la zona Este y ZR es la zona de Reserva geológica, paleontológica, arqueológica y natural Pehuén Co-Monte Hermoso. 


\begin{tabular}{|c|c|c|c|c|}
\hline 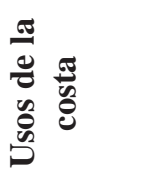 & 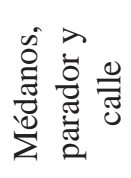 & 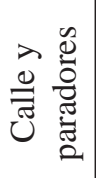 & 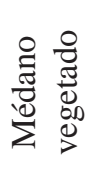 & 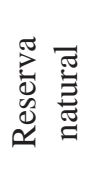 \\
\hline 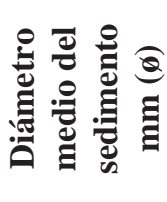 & \begin{tabular}{l}
$\tilde{I}$ \\
\multirow{0}{*}{}
\end{tabular} & 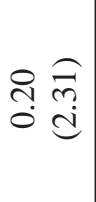 & 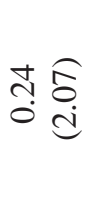 & 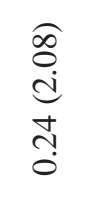 \\
\hline 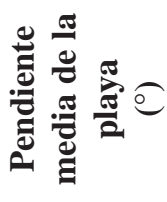 & ๙઼ & 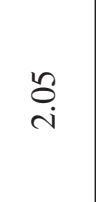 & $\stackrel{9}{-}$ & 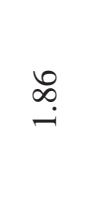 \\
\hline 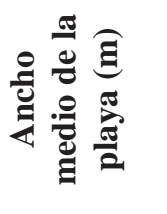 & $\stackrel{8}{0}$ & 으 & $\stackrel{\infty}{\sim}$ & $\stackrel{尺}{ }$ \\
\hline 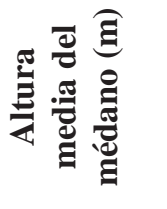 & $\nabla$ & 6 & $n$ & $m$ \\
\hline 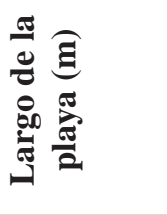 & $\frac{\circ}{a}$ & $\stackrel{n}{\infty}$ & $\stackrel{\text { ̊̊ }}{ \pm}$ & \begin{tabular}{l}
8 \\
\multirow{2}{n}{}
\end{tabular} \\
\hline 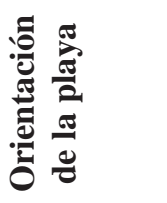 & $\begin{array}{l}\text { II } \\
\text { II } \\
3 \\
3 \\
3\end{array}$ & $\frac{11}{3}$ & 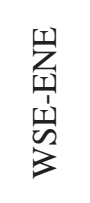 & $\begin{array}{l}1 \\
2 \\
1 \\
1 \\
3 \\
3 \\
3\end{array}$ \\
\hline 莺 & 胥 & U & $\stackrel{\mathbb{N}}{N}$ & $\stackrel{\mathfrak{N}}{N}$ \\
\hline
\end{tabular}


La playa es extensa con sedimento de arena mediana a fina $(0,22 \mathrm{~mm})$. Generalmente se presentan bermas de tormentas contiguas al espaldón. En algunos lugares ocurren afloramientos de rocas terciarias que se cubren con arena ocasionalmente durante el invierno.

Zona Centro (ZC): Con una orientación W-E, es la zona de menor ancho de playa. Su sedimento es el más fino de este balneario, compuesto por arena fina de 0,20 mm $(2,31 \varnothing)$. Por el mismo proceso artificial que la $\mathrm{ZW}$ se encuentran estructuras similares a acantilados pero de mayor altura hacia el Oeste y médanos hacia el Este. Los médanos se encuentran vegetados con tamariscos (Tamarix gallica), los cuales no se observan en las bajadas peatonales a la playa o cuando hay paradores sobre la línea de médanos. Hay afloramientos de roca que quedan al descubierto en época estival a pesar de tener una pendiente mayor que el resto de las zonas. Esta zona coincide con el centro de la villa balnearia, por lo cual el movimiento de personas es mucho mayor respecto de los otros sectores. A partir de marzo de 2010 no se permite el tránsito de vehículos ni lanchas de pescadores sobre la mayor parte de la calle costanera para evitar una erosión mayor en esa porción de playa.

Zona Este (ZE): Es una de las zonas de mayor extensión y posee una orientación WSE-ENE. Sus sedimentos son los más gruesos del área, con arenas medianas de 0,24 mm $(2,07 \varnothing)$. Los afloramientos de roca se encuentran descubiertos durante todo el año, siendo muy extensos en algunos sectores. Coincide con la finalización de la urbanización que se halla más atrás de la primera línea de médanos. Los médanos están vegetados con tamariscos y poseen una altura promedio de $5 \mathrm{~m}$. Los paradores son escasos como las salidas a la playa utilizadas por los bañistas.

Zona Reserva Geológica, Paleontológica, Arqueológica y Natural Pehuén CoMonte Hermoso (ZR): Es la zona de playa más extensa y ancha. Posee una orientación WSW-ENE. Es la playa de menor pendiente con un tamaño de sedimento de arena media de $0,24 \mathrm{~mm}(2,08 \varnothing)$. Los afloramientos de roca se encuentran normalmente cubiertos de arena durante todo el año. En esta zona se descubren afloramientos de arcilla sobre el espaldón que son vestigios de una antigua laguna, que acogen huellas fósiles de animales extintos de aproximadamente 12.000 años. La playa se encuentra enmarcada por una línea de médanos que no supera los $3 \mathrm{~m}$ de altura y están semivegetados con vegetación natural psamófila como, por ejemplo, olivillo (Hyalis argentea), romero amarillo (Senecio subulatus) o una especie endémica de la zona denominada Neosparton ephedroides (Celsi et al., 2010). Detrás de estos se encuentra otra línea de médanos vivos, un poco más elevada $(5 \mathrm{~m})$ y en constante movimiento.

\section{Metodología}

Los datos de viento fueron obtenidos de una estación localizada en el balneario de Pehuén Co (Fig. 3). El intervalo de medición fue de 5 minutos. El período de estudio abarcó de julio de 2007 a diciembre de 2009. Para individualizar los eventos que podían 
modificar el volumen de arena de la playa se clasificaron los datos de viento. Primero según su dirección, es decir se seleccionaron sólo los vientos que soplaron hacia la costa. Se eligieron los cuadrantes SE y SW debido a la orientación Oeste-Este de la costa de Pehuén Co. Estos vientos influyen sobre las olas locales y aumentan la altura de las pleamares.

En una segunda etapa se determinó el umbral mínimo de viento que influye en la modificación de la playa. Pocos estudios establecen un umbral de velocidad de viento que afecte la erosión de las playas. Por ejemplo, Cooper et al. (2004) para identificar el impacto de las tormentas en el Oeste de Irlanda establecieron un umbral de vientos de $46,3 \mathrm{~km} \mathrm{~h}^{-1}$ encontrando un aumento en el número de tormentas de Sur a Norte. En este estudio para obtener el umbral se aplicó la función de densidad de Weibull biparamétrica en la zona de Pehuén Co, la cual se calcula como:

$$
f(v)=\frac{k}{c}\left(\frac{\mid v}{c}\right)^{k-1} \exp \left(-\left(\frac{v}{v}\right)^{k}\right)(v>0)
$$

donde $f(v)$ es la probabilidad de observar una velocidad $v, c$ es el parámetro de escala de Weibull y $k$ el parámetro de forma de Weibull. Básicamente $c$ indica el grado de intensidad del viento, mientras que el coeficiente $k$ indica cuan "aguda" es su distribución (Vitale, 2010).

El coeficiente $c$ presentó un valor de 33,2 para el período de estudio. Este parámetro indica la mediana de la densidad de probabilidades, la cual es muy alta para la zona. En cuanto a $k$ se registró un resultado de 2,61 lo cual indica una alta predominancia de vientos moderados a fuertes. Pehuén Co difiere en sus coeficientes $(k \mathrm{y}$ c) de otras áreas cercanas. El estuario de Bahía Blanca (Fig. 1) posee un $k$ de 2,03 y un c de 26,03 lo que indica una uniformidad anual alta del viento predominando las velocidades leves a moderadas (Vitale, 2010). Tomando estos datos como referencia se elevó $k$ en un $20 \%$ considerando así un umbral de viento de $40 \mathrm{~km} \mathrm{~h}^{-1}$. En base a este umbral se consideraron los períodos de viento que superaron los $40 \mathrm{~km} \mathrm{~h}^{-1}$ por más de 6 h. Cuando disminuyó la intensidad umbral por más de 12 h se consideró como otro evento diferente.

Una vez seleccionados los eventos de viento ocurridos mensualmente fueron relacionados con los perfiles de playa. Los perfiles se midieron mensualmente en todos los sectores (Fig. 3). Se realizaron en sentido perpendicular a la playa, desde los mojones localizados sobre el espaldón de los médanos costeros. Se utilizó el método propuesto por Emery (1961) para el trazado de perfiles de playas. Luego, se calcularon las diferencias volumétricas de los perfiles. El área se calculó considerando un ancho de playa constante e igual a $1 \mathrm{~m}$ y una longitud marcada por el perfil de menor extensión del sector analizado. En el trabajo se incluyó el análisis de dos eventos de viento diferentes para ejemplificar su efecto en los diferentes sectores estudiados. 


\section{Resultados}

\subsection{Frecuencia de eventos de viento fuertes}

El viento medio fue mayor en otoño e invierno, con 44 y $42 \mathrm{~km} \mathrm{~h}^{-1}$ respectivamente. Las ráfagas fueron mayores en verano (superando los $100 \mathrm{~km} \mathrm{~h}^{-1}$ ) y menores en invierno. En primavera predominó una sola dirección de viento (SSW), en el resto de las estaciones la dirección varió considerablemente. La cantidad de horas de vientos superiores a $40 \mathrm{~km} \mathrm{~h}^{-1}$ fue mayor en primavera y otoño superando las $200 \mathrm{~h}$ en cada una de estas estaciones. La menor cantidad de horas de estos eventos se obtuvo en invierno ( 10 h en 2008 y 42 h en 2009). El verano de 2009 fue particularmente mayor en horas de viento fuerte totalizando $471 \mathrm{~h}$.

Los eventos estudiados se incrementaron de 2007 a 2009 (Tabla 2). Entre julio de 2007 y diciembre de 2008 se registraron 46 eventos totalizando $1060 \mathrm{~h}$. Mientras que sólo en 2009 se registraron 45 eventos alcanzando 834 h. La mayoría de los eventos fueron del cuadrante Sudoeste y casi duplicaron la cantidad de horas respecto a los del cuadrante Sudeste en los años 2007 y 2009 (Tabla 3).

\subsection{Cambios en la geomorfología de la playa}

Cada sector de playa tuvo su propia variación en el balance sedimentario respecto de la predominancia de la dirección de los vientos. Las respuestas de erosión de los perfiles se dieron en general en eventos que sucedieron hasta 7 y 8 días antes de la medición del perfil.

La ZW se caracterizó por ser más vulnerable a los vientos del cuadrante Sudoeste. La erosión fue más marcada con eventos del cuadrante SW que no superaron los 7 días previos a la realización del perfil. En casos de eventos con duración no mayor a 7 días del cuadrante SE se produjo acreción.

La zona ZC fue más vulnerable a todas las direcciones de viento. En general, la erosión y acreción se produjeron con todas las direcciones de viento, aunque en algunos eventos la pérdida de sedimentos se llevó a cabo con vientos del cuadrante SW. También se registró incremento de sedimentos en estos perfiles con eventos del cuadrante SE sucedidos pocos días previos al día de medición.

En cambio la zona ZE se caracterizó por ser más vulnerable a los vientos del cuadrante Sudeste. La erosión fue más marcada con eventos de ese cuadrante. Hubo acreción con eventos del cuadrante SW.

La zona ZR presentó mayor vulnerabilidad a los vientos del cuadrante Sudeste que produjeron erosión. Pocos eventos generaron acreción y cuando ocurrió fue debida a los vientos provenientes del cuadrante SW. 
Tabla 2. Eventos de vientos de los cuadrantes SW y SE, mayores a $40 \mathrm{~km} \mathrm{~h}^{-1}$ y con duración de más de 6 h sucedidos en la localidad de Pehuén Co entre julio de 2007 y diciembre de 2009

\begin{tabular}{|c|c|c|}
\hline $\begin{array}{c}\text { Fecha } \\
\text { del } \\
\text { evento }\end{array}$ & $\begin{array}{c}\text { Dirección } \\
\text { predom. } \\
\text { del viento }\end{array}$ & $\begin{array}{c}\text { Duración } \\
\text { (hs) }\end{array}$ \\
\hline $26 / 07 / 07$ & SW & 25 \\
\hline $09 / 08 / 07$ & WSW & 35 \\
\hline $16 / 08 / 07$ & SSW & 7 \\
\hline $06 / 10 / 07$ & SW & 7 \\
\hline $07 / 10 / 07$ & ESE & 6 \\
\hline $26 / 10 / 07$ & WSW & 15 \\
\hline $31 / 10 / 07$ & SW & 16 \\
\hline $09 / 11 / 07$ & SE & 23 \\
\hline $20 / 11 / 07$ & ESE & 27 \\
\hline $22 / 11 / 07$ & SSW & 25 \\
\hline $25 / 11 / 07$ & S & 14 \\
\hline $03 / 12 / 07$ & SE & 24 \\
\hline $09 / 12 / 07$ & W & 9 \\
\hline $11 / 12 / 07$ & W & 6 \\
\hline $14 / 12 / 07$ & SSW & 26 \\
\hline $17 / 12 / 07$ & SSE & 7 \\
\hline $20 / 12 / 07$ & SSE & 26 \\
\hline $23 / 12 / 07$ & SE & 26 \\
\hline $30 / 12 / 07$ & W & 28 \\
\hline $02 / 01 / 08$ & SSE & 30 \\
\hline $10 / 01 / 08$ & WSW & 17 \\
\hline $17 / 02 / 08$ & ESE & 23 \\
\hline $12 / 03 / 08$ & SE & 19 \\
\hline $21 / 03 / 08$ & SSE & 22 \\
\hline $26 / 03 / 08$ & S & 11 \\
\hline $13 / 04 / 08$ & WSW & 28 \\
\hline $28 / 04 / 08$ & WSW & 37 \\
\hline $06 / 05 / 08$ & SSW & 10 \\
\hline $15 / 05 / 08$ & SSW & 16 \\
\hline $21 / 05 / 08$ & WSW & 63 \\
\hline $28 / 05 / 08$ & WSW & 30 \\
\hline
\end{tabular}

\begin{tabular}{|c|c|c|}
\hline $\begin{array}{c}\text { Fecha } \\
\text { del } \\
\text { evento }\end{array}$ & $\begin{array}{c}\text { Dirección } \\
\text { predom. } \\
\text { del viento }\end{array}$ & $\begin{array}{c}\text { Duración } \\
\text { (hs) }\end{array}$ \\
\hline $14 / 06 / 08$ & WSW & 32 \\
\hline $30 / 06 / 08$ & SW & 10 \\
\hline $13 / 09 / 08$ & SW & 16 \\
\hline $18 / 09 / 08$ & SSW & 53 \\
\hline $24 / 10 / 08$ & SE & 17 \\
\hline $26 / 10 / 08$ & SSW & 10 \\
\hline $05 / 11 / 08$ & W & 17 \\
\hline $17 / 11 / 08$ & ESE & 42 \\
\hline $29 / 11 / 08$ & ESE & 17 \\
\hline $04 / 12 / 08$ & ESE & 36 \\
\hline $08 / 12 / 08$ & SE & 59 \\
\hline $16 / 12 / 08$ & SE & 17 \\
\hline $18 / 12 / 08$ & ESE & 14 \\
\hline $27 / 12 / 08$ & SSW & 37 \\
\hline $30 / 12 / 08$ & SE & 25 \\
\hline $01 / 01 / 09$ & ESE & 11 \\
\hline $02 / 01 / 09$ & WSW & 8 \\
\hline $03 / 01 / 09$ & W & 7 \\
\hline $05 / 01 / 09$ & ESE & 81 \\
\hline $10 / 01 / 09$ & ESE & 45 \\
\hline $15 / 01 / 09$ & S & 21 \\
\hline $18 / 01 / 09$ & SSE & 23 \\
\hline $24 / 01 / 09$ & SSW & 28 \\
\hline $27 / 01 / 09$ & ESE & 9 \\
\hline $28 / 01 / 09$ & ESE & 7 \\
\hline $31 / 01 / 09$ & SSW & 28 \\
\hline $02 / 02 / 09$ & SE & 13 \\
\hline $05 / 02 / 09$ & WSW & 32 \\
\hline $08 / 02 / 09$ & ESE & 6 \\
\hline $10 / 02 / 09$ & SW & 24 \\
\hline $16 / 02 / 09$ & W & 15 \\
\hline
\end{tabular}

\begin{tabular}{|c|c|c|}
\hline $\begin{array}{c}\text { Fecha } \\
\text { del } \\
\text { evento }\end{array}$ & $\begin{array}{c}\text { Dirección } \\
\text { predom. } \\
\text { del viento }\end{array}$ & $\begin{array}{c}\text { Duración } \\
\text { (hs) }\end{array}$ \\
\hline $01 / 03 / 09$ & SE & 37 \\
\hline $29 / 03 / 09$ & W & 35 \\
\hline $31 / 03 / 09$ & SSW & 18 \\
\hline $04 / 04 / 09$ & W & 15 \\
\hline $06 / 04 / 09$ & SW & 12 \\
\hline $07 / 04 / 09$ & SSE & 14 \\
\hline $13 / 04 / 09$ & SSE & 12 \\
\hline $17 / 04 / 09$ & SSW & 8 \\
\hline $18 / 04 / 09$ & SSW & 22 \\
\hline $05 / 05 / 09$ & W & 6 \\
\hline $07 / 05 / 09$ & S & 12 \\
\hline $10 / 05 / 09$ & SW & 8 \\
\hline $11 / 05 / 09$ & SSW & 21 \\
\hline $13 / 05 / 09$ & WSW & 19 \\
\hline $17 / 05 / 09$ & SW & 8 \\
\hline $20 / 06 / 09$ & WSW & 12 \\
\hline $23 / 06 / 09$ & WSW & 14 \\
\hline $21 / 08 / 09$ & W & 16 \\
\hline $07 / 09 / 09$ & SSW & 39 \\
\hline $18 / 09 / 09$ & SW & 19 \\
\hline $21 / 09 / 09$ & SSE & 16 \\
\hline $26 / 09 / 09$ & S & 32 \\
\hline $06 / 10 / 09$ & WSW & 13 \\
\hline $11 / 10 / 09$ & SW & 10 \\
\hline $30 / 10 / 09$ & SW & 11 \\
\hline $23 / 11 / 09$ & ESE & 14 \\
\hline $02 / 12 / 09$ & SSE & 13 \\
\hline $05 / 12 / 09$ & SE & 8 \\
\hline $14 / 12 / 09$ & WSW & 12 \\
\hline
\end{tabular}


Tabla 3. Horas de viento fuerte hacia la costa de Pehuén Co registrados entre julio de 2007 y diciembre de 2009. (*) Valores de julio a diciembre de 2007

\begin{tabular}{|c|c|c|c|}
\hline \multirow{2}{*}{ Cuadrante } & \multicolumn{3}{|c|}{ Duración del viento (hs) } \\
\cline { 2 - 4 } & $\mathbf{2 0 0 7} *$ & $\mathbf{2 0 0 8}$ & $\mathbf{2 0 0 9}$ \\
\hline SW & 213 & 387 & 525 \\
\hline SE & 139 & 321 & 309 \\
\hline TOTAL & $\mathbf{3 5 2}$ & $\mathbf{7 0 8}$ & $\mathbf{8 3 4}$ \\
\hline
\end{tabular}

\subsection{Ejemplos típicos del efecto de vientos fuertes sobre la geomorfología de la playa}

Velocidades de viento superiores a $40 \mathrm{~km} \mathrm{~h}^{-1}$, provenientes de los cuadrante SW y SE producen diversos efectos a lo largo de la costa de Pehuén Co. A continuación se presentan dos ejemplos del efecto de vientos fuertes sobre la morfología de la playa. Un evento de vientos del cuadrante SE y otro del cuadrante SW. Cabe destacar que estos vientos generan olas y corrientes litorales fuertes que producen la erosión o acreción de sedimentos en la playa y por lo tanto afectan su geomorfología.

31 de Octubre de 2007. El evento, ocurrido en las playas de Pehuén Co el 31 de octubre de 2007, fue ocasionado por el desplazamiento de un centro de baja presión desde el extremo sur de Argentina con dirección SW-NE (Fig. 4). El viento del SW alcanzó ráfagas máximas de $66 \mathrm{~km} \mathrm{~h}^{-1}$. La velocidad aumentó de 30 a $50 \mathrm{~km} \mathrm{~h}^{-1}$ en pocos minutos y sopló durante $16 \mathrm{~h}$.

Durante la pleamar el efecto de las olas llegó a la base del acantilado y alcanzaron las zonas más altas de la playa contra los médanos costeros y las construcciones. Fue un fenómeno de corta duración (16 h) y de gran poder erosivo dado que el sistema de baja presión se desplazó rápidamente sobre el océano.

En el análisis de la respuesta de los perfiles a este evento (Fig. 5) se encontró que en la ZW hubo una pérdida de $8,6 \mathrm{~m}^{3}$ de sedimento. El perfil permaneció muy similar a las condiciones pre-evento. La berma se redujo en $7,8 \mathrm{~m}^{3}$ y avanzó la barra de lavado. También se modificó la zona del espaldón. Se observó una disminución importante de arena debajo de un parador en el extremo Este de esta zona. En el área se contemplaron algunos troncos de árboles cortados que el mar llevó a este sector durante el evento y gran cantidad de resaca sobre toda la playa. En cuanto a la granulometría del sedimento se encontró un aumentó de tamaño en todos los sectores estudiados excepto en el médano. En este sector de playa disminuyó su $\mathrm{D}_{50}$ de 0,28 a 0,24 mm (1,85 a 2,04 ø). El mayor aumento se produjo en la línea de bajamar donde el $\mathrm{D}_{50}$ cambió de 0,14 a 0,25 mm (Fig. 6). 


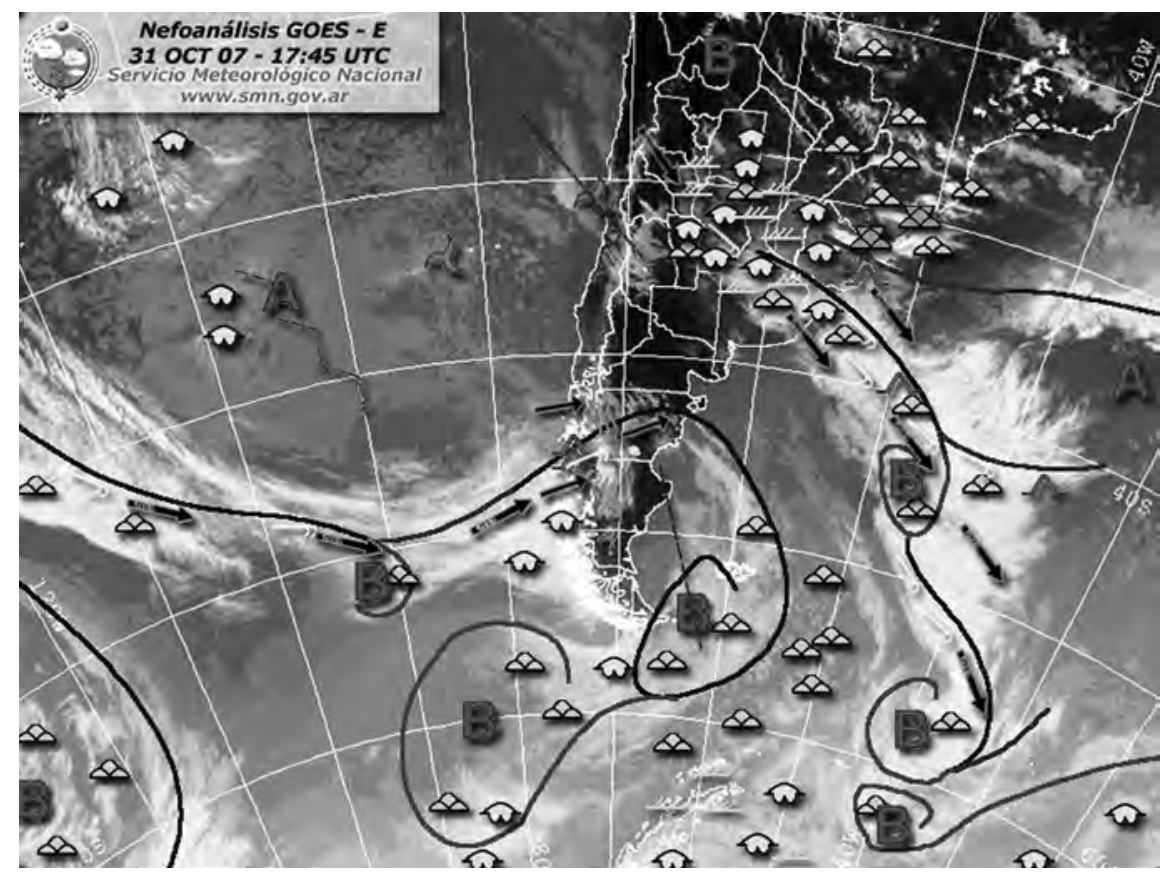

Figura 4. Carta sinóptica y nefoanálisis del día 31 de octubre de 2007. Servicio Meteorológico Nacional (www.smn.gov.ar).

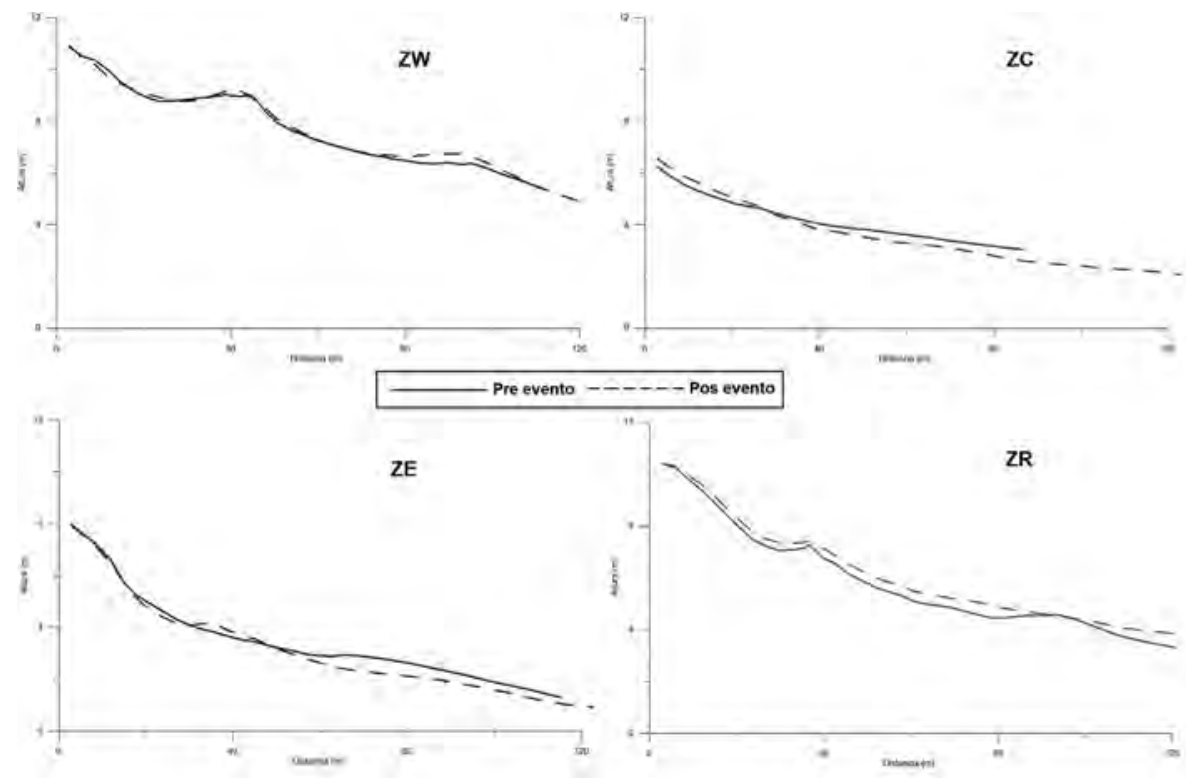

Figura 5. Perfiles de los 4 sectores de Pehuén Co antes y después del evento del 31 de octubre de 2007. Eje vertical exagerado para visualizar los cambios. 

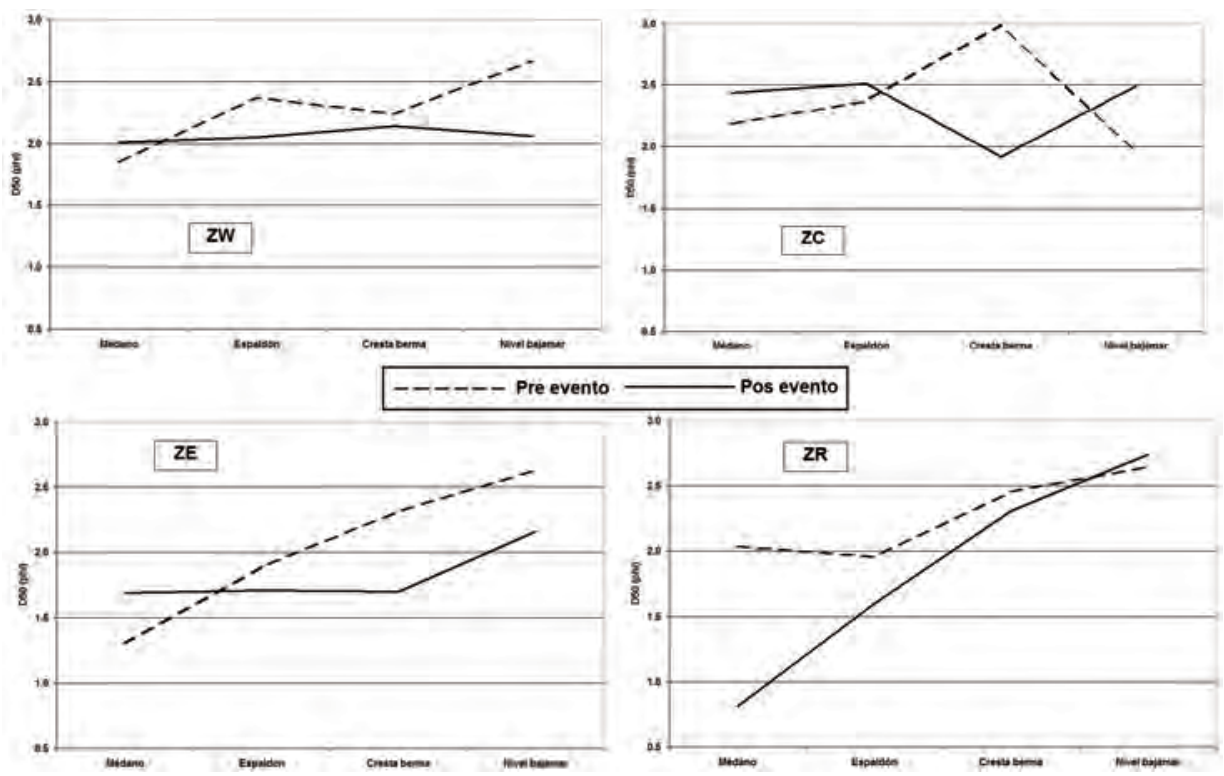

Figura 6. Cambios en el tamaño del sedimento $D_{50}$ causado por el evento del 31 de octubre de 2007 en las 4 zonas de estudio.

En cuanto al perfil de la zona céntrica del balneario (ZC) tuvo una ganancia de volumen total de $0,7 \mathrm{~m}^{3}$. En la zona del espaldón disminuyó su volumen $\left(5,6 \mathrm{~m}^{3}\right)$ lo que representó una clara erosión del mismo. El resto de la playa presentó una acumulación de sedimentos de $6,3 \mathrm{~m}^{3}$. La erosión ocasionó algunos daños en infraestructuras ubicadas sobre el espaldón. También se erosionó un médano vegetado lindero a un parador, perdiendo los tamariscos que lo fijaban. La granulometría del sedimento tuvo una amplia variación en la zona de la playa posterior variando de arena muy fina de 0,12 $\mathrm{mm}$ a mediana de $0,25 \mathrm{~mm}\left(\mathrm{D}_{50}\right.$ de 2,99 a $\left.1,92 \varnothing\right)$. El resto de la playa disminuyó el tamaño medio de los sedimentos, manteniendo $\mathrm{su}_{50}$ en arena fina (entre 0,25 y $0,18 \mathrm{~mm}$ ).

El sector ZE presentó geoformas más suaves, con ganancia de sedimentos de 24,3 $\mathrm{m}^{3}$. En el espaldón se suavizó el pequeño acantilado que presentaba resabio de tormentas anteriores. El resto de la playa subaérea ganó sedimentos formando una ancha barra sobre la mitad de la playa. La pendiente de este perfil disminuyó, variando de 2,6 a 2,3 ${ }^{\circ}$ de inclinación. El $\mathrm{D}_{50}$ del sedimento presentó un comportamiento similar a ZW. En la muestra de sedimentos de la cresta de berma se observó la mayor diferencia, aumentando el tamaño medio de la arena de 0,20 a $0,31 \mathrm{~mm}$.

En general la granulometría de los sedimentos presentó en todos los perfiles una disminución del tamaño en la zona de médanos debido a que la erosión provocada por las olas se llevó la arena más gruesa dejando arena antigua más fina al momento del muestreo. Solo en $\mathrm{ZR}$ su $\mathrm{D}_{50}$ marcó un paso de arena fina a gruesa (de 0,24 a 0,57 
mm) después del evento. Esto se debió a que la muestra de sedimento fue de rezago del viento. En esta zona (ZR) se obtuvo una ganancia general de $15,2 \mathrm{~m}^{3}$. Su pendiente se suavizó $\left(2,4\right.$ a $\left.2,2^{\circ}\right)$. La berma y los canales no se observaron más. A partir del espaldón la playa tuvo una amplia ganancia de sedimentos y suavizado del perfil.

26 de marzo de 2008. El evento ocurrido el 26 de marzo de 2008 fue de características diferentes al explicado anteriormente. Este evento fue ocasionado por el desplazamiento de un amplio centro de baja presión que se movía por la plataforma continental patagónica hacia el océano Atlántico con dirección SW-NE (Fig. 7). Esto ocasionó la diferencia con el evento anterior, proporcionando un viento con predominancia de la dirección S-SSE con ráfagas máximas de $58 \mathrm{~km} \mathrm{~h}^{-1}$. La velocidad aumentó de 30 a $45 \mathrm{~km} \mathrm{~h}^{-1}$ en pocos minutos y se extendió durante $11 \mathrm{~h}$. A los fuertes vientos hacia la costa se sumó la presencia de la pleamar, que facilitó que las olas alcanzasen el espaldón y las construcciones (Fig. 8). Las precipitaciones se presentaron 5 h después del evento.

Al analizar la respuesta de los perfiles a este evento (Fig. 8) se encontró que la zona ZW presentó ganancia de sedimentos acumulando $34,7 \mathrm{~m}^{3}$. El médano y espaldón per-

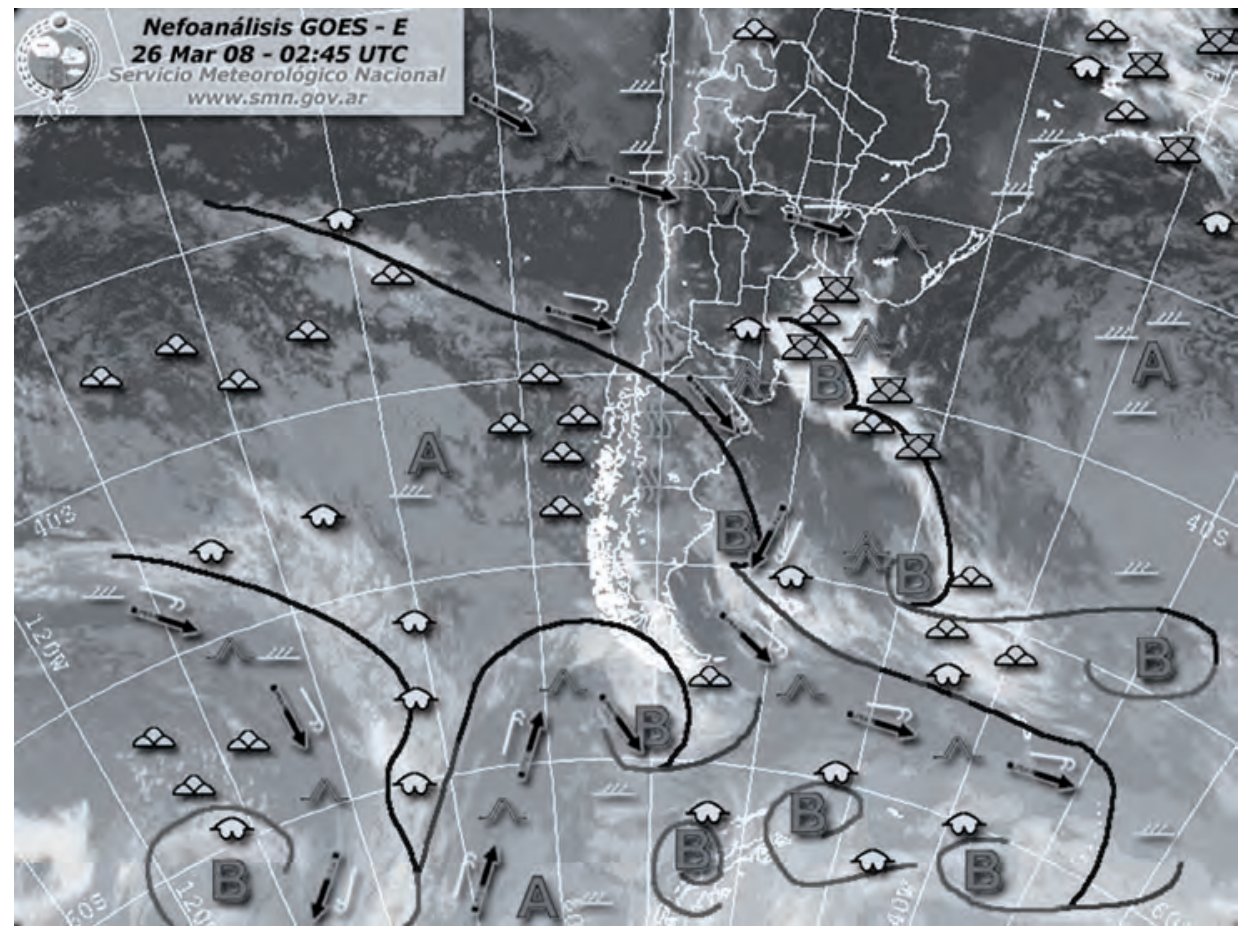

Figura 7. Carta sinóptica y nefoanálisis del día 26 de marzo de 2008. Servicio Meteorológico Nacional (www.smn.gov.ar). 


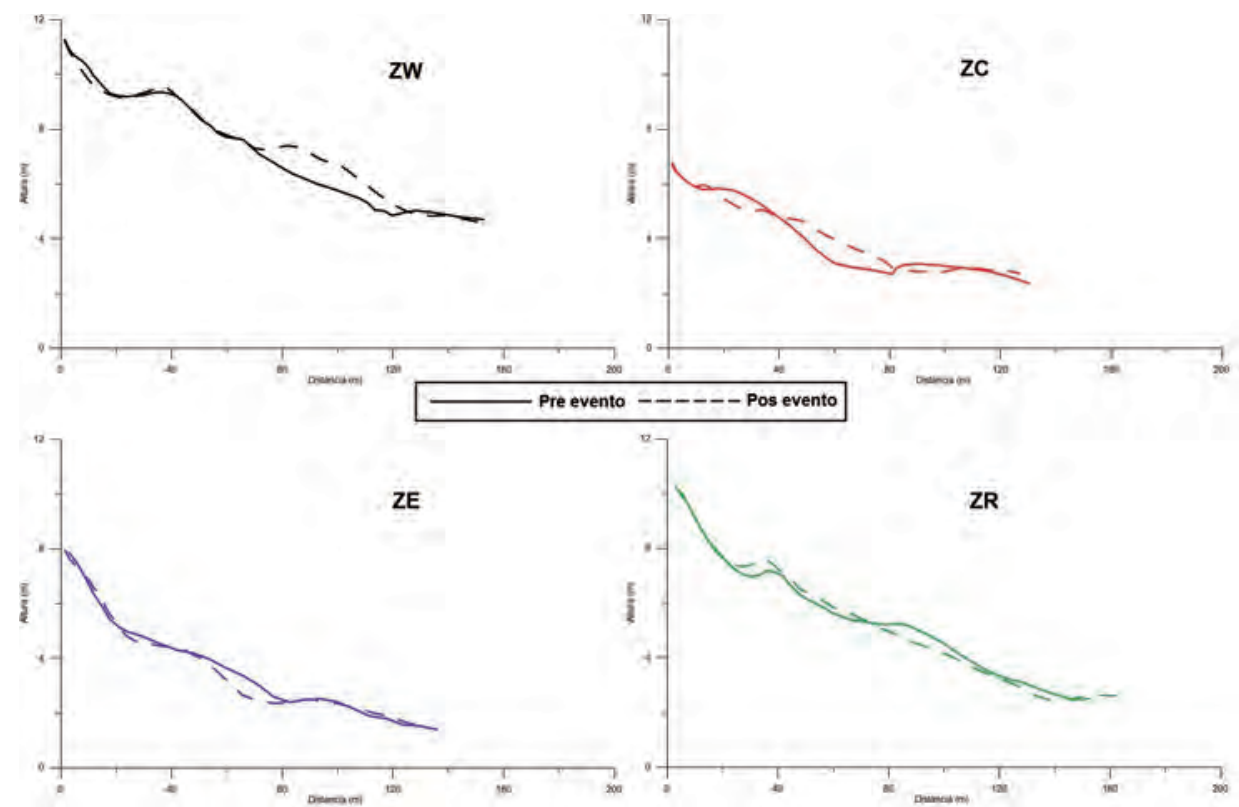

Figura 8. Perfiles de los 4 sectores de Pehuén Co antes y después del evento del 26 de marzo de 2008. Eje vertical exagerado para visualizar los cambios.

manecieron similares a las condiciones pre-evento. No se apreció ningún tipo de erosión en la zona del pie de médano. La playa subaérea cambió su aspecto con la presencia de una pronunciada berma de $37,6 \mathrm{~m}^{3}$ que comenzó en el espaldón.

El perfil de la zona céntrica (ZC) del balneario presentaba una berma y un profundo canal cerca de la línea de bajamar. Después de este evento la berma avanzó hacia el mar tapando el canal. Más tarde se formó un amplio canal que proseguía por debajo de la línea de agua. Este sector de playa tuvo como balance final una acumulación de sedimentos de $12,9 \mathrm{~m}^{3}$.

El sector ZE fue más expuesto al viento que los perfiles anteriores. Tuvo una erosión de sedimentos de 2,3 $\mathrm{m}^{3}$. El espaldón se erosionó $\left(1,7 \mathrm{~m}^{3}\right)$ formando un pequeño acantilado. En la berma que había en el perfil pre-evento se formó un canal, con lo que se produjo una pérdida de sedimentos de $9 \mathrm{~m}^{3}$. La barra cercana a la línea de bajamar continuó presente en el perfil post-evento.

El sector ZR tuvo una pérdida general de 3,9 $\mathrm{m}^{3}$. Esta se registró en la desaparición de la berma y la profundización del canal. Su pendiente varió de 1,6 a 1,8 ${ }^{\circ}$ de inclinación. A partir del espaldón se descubrieron amplias planchuelas escalonadas de afloramientos de arcilla (los que contienen huellas fósiles y le dan la categoría de reserva a esta zona). 


\section{Discusión}

Sólo en primavera se observó una predominancia neta del SSW. Por este motivo no se percibió ningún indicio de ganancia o pérdida de sedimentos estacionales. Como tendencia general se observó que los perfiles de todas las zonas comenzaron una recuperación de sedimentos después de los 7 u 8 días posteriores al evento. Esto mismo sucedió en las playas entre Chipiona y Rota (Cádiz, España) donde Anfuso y del Río (2003) observaron una tasa de recuperación uniforme en el tiempo de uno a tres meses luego de eventos erosivos a pesar de sus diferentes características geomorfológicas.

En Pehuén Co se registraron 91 eventos en los 29 meses analizados. El 57\% de ellos fueron del cuadrante SW, 37\% del SE y sólo un 6\% provinieron de la dirección Sur. Esto generó mayor vulnerabilidad a la erosión y cambios en la geomorfología de algunas zonas respecto a otras. Esta vulnerabilidad es resultado de las características del entorno de la playa. Una tormenta ocasiona efectos diferentes en los perfiles de playa de distintas áreas de una costa (Lee et al., 1998). Esto se observó en el caso de Ludlam Island (New Jersey, USA). Esta playa presentó diferentes respuestas a lo largo de su costa ante la tormenta del 19 de diciembre de 1977 debido a una serie de espigones en el sector medio de su costa (Birkemeier, 1979). Lo mismo analizó Hill et al. (2004) en las playas de arena del Sur de Maine (USA). Ellos encontraron que playas con un entorno desarrollado, es decir más modificadas por el hombre (viviendas, calles, vegetación, etc.) presentaban una mayor vulnerabilidad ante determinadas tormentas que otras playas moderadamente desarrolladas o sin desarrollar.

Varios autores enfatizan los perjuicios que ocasionan en la provincia de Buenos Aires los vientos de los cuadrantes SE y SW. En el Norte, Bértola et al. (2006) evidenció un gran aumento de pendiente en la playa a causa de la acción de olas y vientos del SW. También Marcomini y López (1997) y Fiore et al. (2009) coincidieron al afirmar el efecto erosivo sobre las playas y la elevación del nivel medio del mar ocasionado por los vientos del cuadrante SE. Asimismo a $20 \mathrm{~km}$ al Este de Pehuén Co se observaron diferentes tormentas y sus efectos sobre la geomorfología de la playa concluyendo que las olas y vientos del cuadrante SE, ocasionan grandes daños en la costa (Caló et al., 2000) como así también los eventos del SW (Bustos et al., 2009).

La planificación del uso del suelo requiere estudios previos de los eventos que ocasionan daños a la costa. Luego de ese análisis es posible el trazado de mapas de vulnerabilidad y planificación del desarrollo urbano costero. Así lo hicieron Rodríguez-Ramírez et al. (2003) cuando presentaron un mapa de planificación para los futuros cambios en el uso de la tierra en la zona del SW español en base a los daños ocasionados por las tormentas. También Benavente et al. (2007) en el NE marroquí realizó un mapa de vulnerabilidad frente al embate de temporales del NE midiendo su exposición en alto, medio y bajo, siendo el sector sur de la zona de estudio la de más alto impacto. Ante estas evidencias y en base al registro de eventos y sus efectos sobre el uso y características de la costa se realizó un mapa de vulnerabilidad de las diferentes zonas (Fig. 9). 


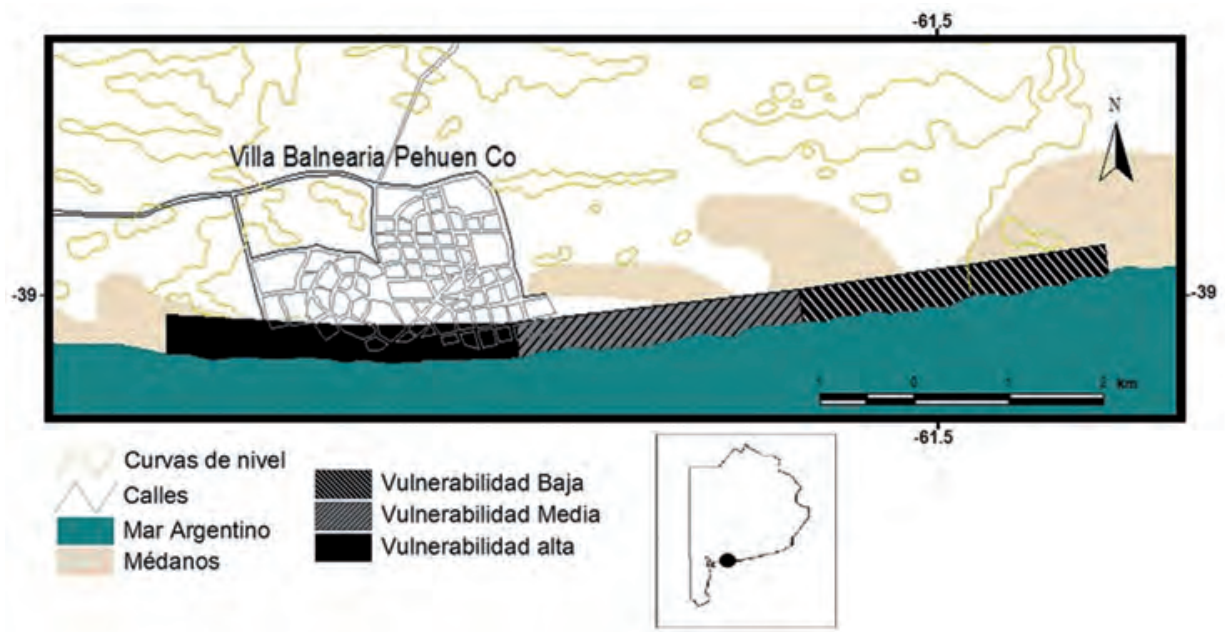

Figura 9. Mapa de vulnerabilidad de las diferentes zonas del balneario Pehuén Co.

De esta forma la mayor vulnerabilidad la presentaron las zonas ZW y ZC debido a que fueron más afectadas por los vientos del cuadrante SW. Estos vientos predominaron durante todo el año y por ello se incrementó el riesgo de pérdidas de sedimentos en la zona urbanizada. A esto se sumó las construcciones realizadas sobre el espaldón del médano (calles, paradores, baños, etc.) que, al quedar al descubierto ante la acción del oleaje de tormenta, generaron geoformas similares a acantilados. Estos fueron directamente erosionados en cada evento, tal como sucedió el 21 de agosto de 2009 cuando se derrumbó parte de la calle costanera por una fuerte tormenta del SW. Aunque ZC no presentó tantas pérdidas por los vientos del cuadrante $\mathrm{SW}$, los daños ocasionados fueron tan o más perjudiciales que los de ZW. Esto se debe a la mayor cantidad de área de médanos vegetados artificialmente en la ZW que no permite el intercambio natural de sedimentos en casos de eventos extremos. En ZC se registró la mayor pendiente y menor ancho de playa. También se encontró la mayor cantidad de asentamiento urbano e infraestructura sobre la costa (calle costanera, paradores y bajadas de turistas a la playa) lo que causó mayores daños económicos en cada evento erosivo. Además, eventualmente, se fue desarrollando el mismo proceso artificial que genera geoformas semejantes a acantilados, como en ZW, debido a las construcciones sobre el médano. Esta vulnerabilidad, en ambos sectores, también fue observada en un evento de olas del 26 de julio de 2007 donde las olas acompañadas de viento del SW erosionaron ambas zonas y acumularon sedimentos en las zonas del Este del balneario (Bustos et al., 2009).

En cuanto a ZE se encontró en una situación menos vulnerable que ZW y ZC. Esto se debió a que la urbanización no estaba tan cercana a la primera línea de médanos en la mayor parte de la zona. También a que los eventos de erosión se generaron especialmente por vientos provenientes del cuadrante SE que no fueron los predominantes del área. A pesar de este bajo riesgo la vulnerabilidad aumentó por la gran vegetación artificial 
que tienen sus médanos hasta el espaldón. Sumado a esto en la zona hubo grandes áreas de afloramientos descubiertos durante todo el año lo cual indicó la poca disponibilidad de sedimentos sobre la playa frontal.

La zona menos vulnerable a la erosión fue ZR. No fue afectada por los vientos predominantes del cuadrante SW. Además no posee urbanización ni infraestructuras y se restringió el paso de vehículos desde mediados del año 2009. Tampoco se observaron afloramientos descubiertos en la playa frontal, solo en algunos sectores de la playa posterior. A pesar de esto la vulnerabilidad no fue nula debido a que posee un patrimonio natural de huellas fosilizadas de más de 10000 años. Estas se esparcieron sobre planchuelas de arcilla cementada que se observaron especialmente en las zonas subaéreas y de lavado. Generalmente se encontraron cubiertas de sedimento arenoso que actuaba como amortiguador para su conservación. Pero ante eventos del cuadrante SE los sedimentos dejaron al descubierto los afloramientos y expuestas estas huellas a la erosión marina, por lo cual se otorgó un cierto grado de vulnerabilidad a esta zona.

\section{Conclusiones}

Los vientos fuertes con direcciones hacia la playa ocasionaron diferentes cambios en la geomorfología del balneario Pehuén Co. Las zonas ZW y ZC fueron las más erosionadas ante eventos del cuadrante SW. En cambio las zonas ZE y ZR disminuyeron sus perfiles por erosión respondiendo a los efectos de los vientos del cuadrante SE.

Con estos resultados se logró definir el mapa de vulnerabilidad de la costa de Pehuén Co. Se delimitó como áreas más vulnerables las zonas ZW y ZC por su mayor impacto antrópico y por su exposición y respuestas geomorfológicas a los vientos del cuadrante SW, dominantes en los eventos estudiados de este área. A la zona ZE se le designó una vulnerabilidad media debido a su menor urbanización y porque los eventos de erosión se generaron con los vientos del cuadrante SE que no son los predominantes de la zona. Por último la zona menos vulnerable a la erosión es ZR porque no posee impacto antrópico y no es afectada por los vientos dominantes del SW.

Como se mencionó anteriormente cuando se analiza el impacto de tormentas es necesario incluir parámetros meteorológicos y oceanográficos. Pero no contar con ellos no puede ser un impedimento para el estudio de vulnerabilidad de los sectores litorales. Cada año aumenta el número de actividades que se desarrollan en ellas, atrayendo población e inversiones. Este incremento del impacto antrópico sobre las costas no debe sumarse a la falta de planificación. Por ello este trabajo representa los primeros pasos para desarrollar un plan de manejo costero en la localidad balnearia de Pehuén Co en base a la definición de los sectores más vulnerables. La costa debe beneficiarse con una adecuada gestión que considere todos los factores de riesgo. Estos estudios deben ser dirigidos a prevenir y controlar la degradación del medio ambiente marino y costero, así como a la recuperación de impactos ocasionados por actividades naturales y antrópicas. 


\section{Agradecimientos}

Este trabajo se realizó con fondos de proyectos de la Universidad Nacional del Sur, CONICET y Agencia Nacional de Promoción Científica y Tecnológica.

\section{Referencias bibliográficas}

AllEN, J.R., (1981). Beach erosion as function of variations in the sediment budget. Sandy Hook, New Jersey. Earth Surface Processes and Landforms, 6: 139-150.

ANFuSO, G., DEL Río, L., (2003). Cuantificación de las variaciones volumétricas y evolución del litoral entre Chipiona y Rota (Cádiz) durante el período 1996-1998. Rev. C. y G., 17 (3-4): 17-27.

Benavente, J., Bello, E., Infuso, G., Nachite D., Macias A., (2007). Sobreelevación debida a temporales y cambios producidos en las playas del litoral NE Marroquí. Rev. C. \& G, 21 (1-1):13-25.

BÉrtola, G. R., Piccolo, M.C., Merlotto, A., (2006). Efecto de la tormenta del 25 de junio del 2006 en la playa de Bahía de los Vientos, Argentina. En: Actas de las IV Jornadas Interdisciplinarias del Sudoeste Bonarense, Universidad Nacional del Sur, 77-82.

BIRKEMEIER, W. A., (1979). The effects of the 19 december 1977 coastal storm on beaches in North Carolina and New Jersey. Shore and Beach, 47:7-15.

Bustos, M. L., Piccolo, M. C., Perillo, G. M. E., (2009). Cambios en la geomorfología de la playa de Pehuén Co debido a la actividad de las olas el 26 de julio de 2007. En: Actas de las V Jornadas Interdisciplinarias del Sudoeste Bonarense, Universidad Nacional del Sur, 97-102.

CAló, J, Espósito, G., CAPUto, R., LizAsoAin, W., (1987). Estudio litoral geológico ambiental (Dinámica sedimentaria). Segundo informe técnico a la municipalidad de Cnel. Rosales, Instituto Argentino de Oceanografía, Bahía Blanca, pp. 58.

Caló, J., Fernández, E., Marcos, A., Aldacour, H., Varela, P., (2000). Comparación del efecto de dos tormentas en la ciudad de Monte Hermoso, Argentina. GEOACTA, 25:40-48.

Capelli de Steffens, A., CAMpo de Ferreras, A., (1994). La transición climática en el Sudoeste Bonaerense, Sigeo N 5, Serie monografías, Bahía Blanca, pp. 76.

Celsi, C. E., MAC-Lean, H. D., YezZI, A., Triches, M. L., (2010). Dunas costeras de la Pampa austral: biodiversidad y conservación entre el río Quequén salado y el balneario Pehuén Co. Buenos Aires, Proyecto costas bonaerenses, pp. 44. 
CoOper, J.A.G., Jackson, D.W.T., NAVAS, F., McKenna, J., Malvarez, G.C., (2004). Identifying storm impacts on an embayed, high-energy coastline: examples from western Ireland. Marine Geology, 210: 261-280.

Delgado, A. L., Perillo, G. M. E., Piccolo, M. C., (2009). Validación del modelo SMARA/WAM en la zona costera de Pehuén Co y Monte Hermoso, Argentina. En: VII Jornadas Nacionales de Ciencias del Mar, Instituto Argentino de Oceanografía, Bahía Blanca, 13.

Del Pozo, O., BazÁn, S., Rosell, M., (2000). El turismo, la apropiación de los recursos costeros y la preservación del ambiente. Un estudio de caso en el suroeste bonaerense. En: Turismo: Desarrollo local y regional. (Bróndolo, M. y otros, Eds.). Ediuns, Bahía Blanca, 145-160.

EMERY, K. O., (1961). A simple method of Measuring beach profiles. Limnology and Oceanography, 6 (1): 90-93.

Fiore, M., D’Onofrio, E. E., Pousa, J. L., Schnack, E. J., Bértola, G. R., (2009). Storm surge and coastal impacts at Mar del Plata, Argentina. Continental Shelf Research, 29: 1643-1649.

Gibeaut, J. C., GutiÉRrez, R. HePner, T. L., (2002). Threshold conditions for episode beach erosion along the southeast Texas coast. Gulf Coast. Association of Geological Societies Transaction, 52: 1-13.

Hill, H. W., Kelley, J. T., Belknap, D. F., Dickson, S. M., (2004). The effects of storms and storm-generated currents on sand beaches in Southern Maine, USA. Marine Geology, 210: 149-168.

LEATHERMAN, S. P., (1979). Beach and dune interactions during storm conditions. Quarterly Journal of Engineering Geology \& Hydrogeology, 12: 281-290.

LeE, G., Nicholls, R., BirkemeIER, W., (1998). Storm-driven variability of the beachnearshore profile at Duck, North Carolina, USA, 1981-1991. Marine geology, 148: 163-177.

LizÁrraga-Arciniega, R., Martínez días de León, A., Delgado GonZÁlez, O., Rodrigo Torres, C., Galindo Bect, L., (2007). Alternancia de los ciclos de erosión/acresión de playa relacionados con el oleaje en Rosarito, Baja California, México. Ciencias Marinas, 33 (3): 259-269.

MEndoZA, E. T., JimÉnEZ, J. A., (2008). Clasificación de tormentas costeras para el litoral catalán (Mediterráneo NO). Ingeniería Hidráulica en México, XXIII (2): 23-34.

MARCOMINI, S., LÓPEZ, R., (1997). Influencia de la urbanización en la dinámica costera, Villa Gesell, provincia de Buenos Aires, República Argentina. Revista de la Asociación Argentina de Sedimentología, 4 (2): 79-96. 
Perillo, G.M.E., (2003). Dinámica del Transporte de Sedimentos. Asociación Argentina de Sedimentología, Publicación Especial Nro. 2, La Plata, pp. 201.

PIEdRA-Cueva, I., (2006). Gestión en la zona costera de rocha: playa La Balconada. En: Memorias del seminario "Un enfoque integrado para la gestión sustentable del agua-Experiencias de cooperación”. Centro de Estudios Transdisciplinarios del Agua (CETA), Universidad de Buenos Aires UBA (sin pp).

Rodríguez-Ramírez, A., Ruiz, F., CÁceres, L., Rodríguez Vidal, J., Pino, R., MuÑOZ, J., (2003). Analysis of the recent storm record in the Southwestern Spanish coast: implications for litoral Management. The Science of the Total Environment, 303: 189-201.

Reyes, J. L., Martins, J. T., Benavente, J., Ferreira, O., Gracia, F. J., Alveirinho-Dias, J. M., LóPEZ-AguAYo, F., (1999). Gulf of Cadiz beaches: A comparative response to storm events. Boletín del Instituto Español de Oceanografía, 15 (1): $221-228$.

SHN, (2010). Tablas de marea. Buenos Aires, Servicio de Hidrografía Naval-Armada Argentina. www.hidro.gov.ar.

Vitale, A., (2010). Modelado y simulación del balance energético en marismas. Tesis doctoral, Departamento de Ingeniería, Universidad Nacional del Sur, pp. 342. 